\title{
Analysis on thermal comfort of clothing with different textile materials through thermal simulation
}

\author{
Muhammad AWAIS, Ellen WENDT, Sybille KRZYWINSKI \\ TU Dresden, Institute of Textile Machinery and High-Performance Material Technology, Germany
}

\begin{abstract}
Thermophysiological comfort is one of the most important aspects of wear comfort. Currently, there are no software solutions available for the combined consideration of material characteristics, fit and thermophysiological behavior. Thus, a laborious empirical process is typically required to determine an appropriate design matching new textile materials for pattern cuts as well as changing climatic conditions. A detailed wear trial in a climatic chamber supports this process. The objective of this research is to analyze the thermal comfort of clothing with different thermal characteristics through the simulation of heat regulation in the human body, microclimate, clothing, and environment.
\end{abstract}

Keywords: 3D body scanning, fitting simulation, human model, thermal simulation, thermal comfort

\section{Introduction}

Thermal comfort has always been a crucial factor in garment design, can be defined as a state of mind that expresses satisfaction with the thermal environment and is assessed by subjective evaluation [1]. Human beings face different environmental conditions throughout their daily routine. Since the environmental parameters (ambient temperature, humidity, and air velocity) that affect thermal comfort are continuously changing, clothing plays a very important role within this scenario of ever changing external factors.

The human body always tries to maintain its core body temperature within a narrow temperature range of $37 \pm 0.5{ }^{\circ} \mathrm{C}$, whereby this temperature is achieved by balancing internal heat production and heat loss to the environment. The human body continuously produces heat due to its metabolism. The metabolism rate depends upon the activity level of the human. When resting, energy is only required for basic body functions, i.e. respiration and heart functions providing oxygen and nutrients to body cells. However, during phases of activity, body muscles need more oxygen and nutrients to perform mechanical work, thus resulting in an increase in the metabolic rate. Excess energy that is not consumed by muscles is then liberated outside the body by conduction, convection, radiation, evaporation, and respiration. The heat balance equation can be written as [2]:

$$
\mathrm{S}=(\mathrm{M}-\mathrm{W})-(E+C+R+B)
$$

Here, heat storage $(S)$ is the difference between heat production (metabolism M corrected for work $W$ ) and heat loss (evaporation $\mathrm{E}$, convection and conduction $\mathrm{C}$, radiation $\mathrm{R}$ and respiration $\mathrm{B}$ ). A body achieves heat balance once the rate of heat storage is zero $(S=0)$. If heat storage increases continuously, in conclusion, the rate of heat production is greater than the rate of heat loss. As the human body has a limited thermal storage capacity, the core body temperature increases as a result. In contrast, if the rate of heat loss is greater than the rate of heat production, the core body temperature decreases. Therefore, the human thermoregulation system has thermal sensors and diverse actuators, such as vasomotion (vasodilation \& vasoconstriction), sweating, and shivering thermogenesis, to maintain the thermal equilibrium of the human body [3].

The main objective of this research is the application of simulation techniques to generate a comprehensive solution for evaluating the thermal comfort of different textile materials while considering climatic conditions, microclimate, fit, drapability and thermal properties of clothing. This simulation process offers an enormous potential for sectors involving outdoor, working, and protective clothing as well as sportswear.

\section{Methodology}

The presented study evaluated thermal comfort of clothing that is constructed with different textile materials; simple clothing ensembles, i.e. a long sleeve shirt and trekking trousers, were selected for this research. In case 1, the material T1 (R/L knit made of PES yarn) and T2 (plain weave made of PA6 yarn) were used for the long sleeve shirt and the trekking trousers, respectively. In case 2, the material T7 (knit made of PES hybrid yarn) and T3 (fleece made of PES yarn) were chosen for the long sleeve shirt and the trekking trousers, respectively. The selected materials were comprehensively characterized. The physical, mechanical and thermal properties that were measured are listed in the following table. 
Table 1. Characterization of the materials

\begin{tabular}{|c|c|c|c|c|c|}
\hline \multirow{2}{*}{ Characteristics } & \multirow{2}{*}{ Instruments } & \multicolumn{4}{|c|}{ Textile material } \\
\hline & & T1 & T2 & T3 & T7 \\
\hline Fabric thickness [mm] & $\begin{array}{c}\text { Karl Schröder KG Material } \\
\text { Testing Machine }\end{array}$ & 0.46 & 0.29 & 1.55 & 0.41 \\
\hline $\begin{array}{l}\text { Average mass per unit } \\
\text { area of the fabrics }\left[\mathrm{g} \mathrm{m}^{-2}\right]\end{array}$ & GSM Cutter, weighing balance & 161 & 125 & 168 & 92 \\
\hline $\begin{array}{l}\text { Water vapor resistance } \\
{\left[\mathrm{m}^{2} \mathrm{~Pa} \mathrm{~W}^{-1}\right]}\end{array}$ & Sweat guarded hot plate & 1.69 & 3.18 & 5.57 & 2.98 \\
\hline $\begin{array}{l}\text { Thermal resistance }\left[\mathrm{m}^{2}\right. \\
\left.\mathrm{K} \mathrm{W}^{-1}\right]\end{array}$ & Sweat guarded hot plate & 0.005 & 0.009 & 0.063 & 0.024 \\
\hline Specific heat $\left[\mathrm{Jkg}^{-1} \mathrm{~K}^{-1}\right]$ & calculated & 493 & 295 & 1640 & 170 \\
\hline $\begin{array}{l}\text { Bending stiffness } \\
{\left[\mu \mathrm{N} \text { m] (warp, weft, } 45^{\circ}\right)}\end{array}$ & $\begin{array}{l}\text { Bending Stiffness tester } \\
\text { Cantilever ACPM } 200\end{array}$ & $\begin{array}{l}1.18 \\
0.74 \\
0.63 \\
\end{array}$ & $\begin{array}{c}3.22 \\
10.32 \\
4.82 \\
\end{array}$ & $\begin{array}{l}2.87 \\
2.88 \\
2.91 \\
\end{array}$ & $\begin{array}{l}1.58 \\
1.28 \\
0.42 \\
\end{array}$ \\
\hline $\begin{array}{l}\text { Tensile stiffness }(\varepsilon=1 \%) \\
{[\mathrm{kPa}] \text { (warp, weft) }}\end{array}$ & Zwick Tensile Strength Tester & $\begin{array}{l}761 \\
448 \\
\end{array}$ & $\begin{array}{c}6445 \\
38766\end{array}$ & $\begin{array}{l}646 \\
289 \\
\end{array}$ & $\begin{array}{l}434 \\
310\end{array}$ \\
\hline
\end{tabular}

A test person was selected and scanned with the help of the 3D body scanner VITUS [4] to conduct further simulation processes. Body measurements were taken from the scanned data according to the norms ISO 8559 and DIN EN ISO 7250. These measurements were used to develop the 2D patterns for the trousers and the long sleeve shirt with the help of the software Grafis [5].

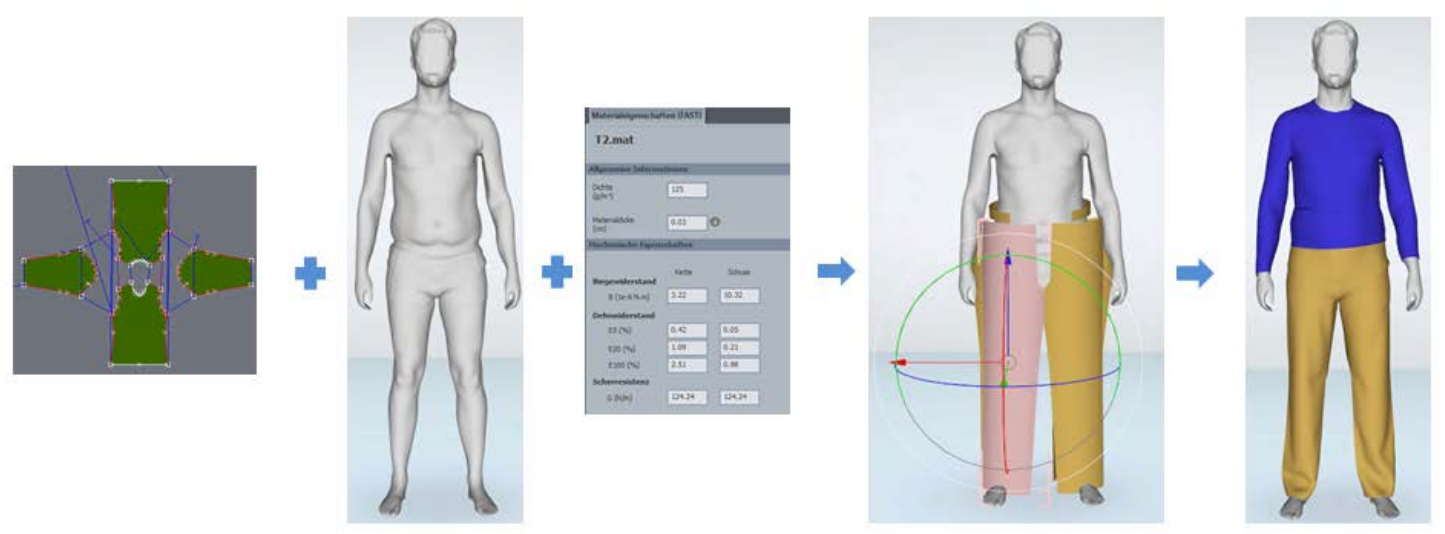

Fig. 1. Process chain of $3 D$ fit simulation (defining of seams, assigning material properties, positioning of cutpatterns, and simulation).

The 3D fit simulation of these garments was carried out by means of the software Modaris V8 [6]. This software gives the opportunity to simulate clothing including the draping properties of the fabric. Thus, the fit simulations were performed according to the selected materials for two different cases Fig. 1 illustrates the process chain of the 3D fit simulation.

The thermal simulation of the system Body - Clothing - Environment was conducted by use of the software Theseus-FE [7]. As a first step towards thermal simulation, a thermophysiological virtual model of the test person was developed. For this purpose, the scanned model of the test person was coupled with the Fiala Model [8] that is available in Theseus-FE. Moreover, the results of the 3D fit simulation were also imported into that same software.

The air gap thickness has a considerable influence on the thermoregulation of the human body and is not uniformly distributed throughout the body. Therefore, the clothing was divided into air zones with respect to the thickness of air gaps and their location on the body (Fig. 5). The heat transfer coefficient of each air zone was calculated. The processes of coupling the Fiala Model with the scanned data of the test person, dividing the air gaps into air zones, and calculating the heat transfer coefficient have already discussed comprehensively in a previous publication [9]. 


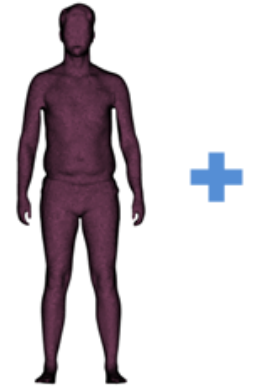

Individual scanned data

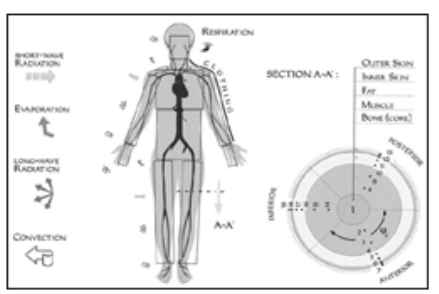

Fiala model

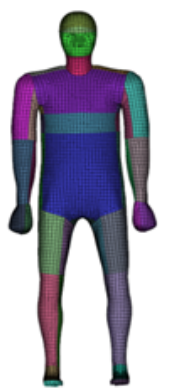

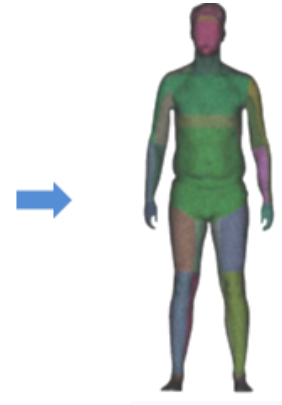

Thermophysiological model for individualscanned data

Fig. 2. Development of a thermophysiological model of the test person

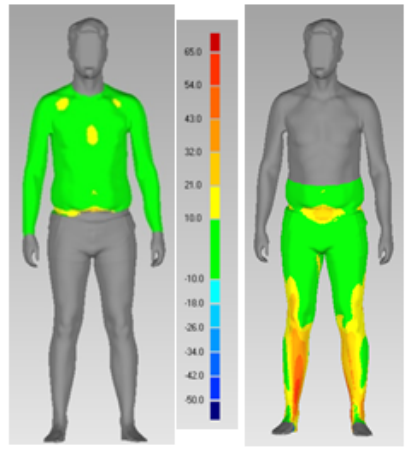

Analyzing of air gaps between body and clothing

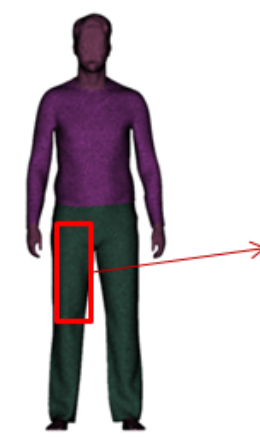

Thermophysiological model

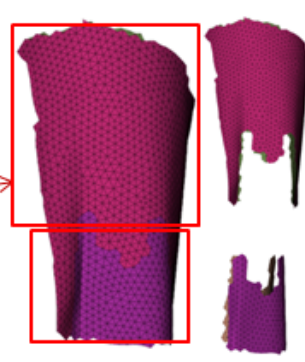

Defining the air zones

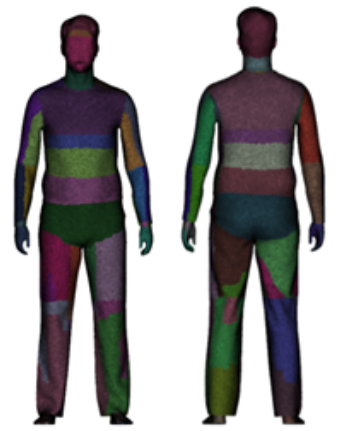

Different colors show different air zones

Fig. 3. Defining air zones by dividing air gaps with respect to their thickness and location on the body

After defining all the required boundary conditions regarding the heat transfer due to convection, radiation, clothing material properties, and outside environment $\left(23^{\circ} \mathrm{C}, 50 \% \mathrm{RH}, \& 0.3 \mathrm{~m} / \mathrm{sec}\right)$, thermal simulation was executed.

\section{Results and discussion}

The main parameters (core body and mean skin temperatures), which are responsible for thermal comfort, are illustrated in Fig. 4 for both cases. The trend of body core temperature is identical in both cases due to the active system of the Fiala model that also functions the same in both cases. Both graphs of mean skin temperature illustrate the same trend as well although there are some minor variations in values. The mean skin temperature in case 2 ( T7 \& T3) is slightly higher as compared to case 1 , which results from the higher thermal resistance of the fabric in case 2 , cf. Table 1.

Once the simulation begins, the mean skin and core temperature start to reduce due to the influence of the outside environment $\left(23^{\circ} \mathrm{C} \& \mathrm{RH} \% 50\right)$. However, as soon as the $2^{\text {nd }}$ phase sets in, the activity level increases from 1 Met $(0 \mathrm{~km} / \mathrm{h})$ to $3.2 \mathrm{Met}(4 \mathrm{~km} / \mathrm{h})$ so that internal heat production also increases due to a rising high metabolism rate. Hence, both temperatures (core \& skin) start to increase in the middle of the 2 nd phase. Although the $3^{\text {rd }}$ phase involves resting $(0 \mathrm{~km} / \mathrm{h})$, a slight increase in both temperatures can still be noticed. This phenomenon results from the large amount of energy produced by the test person in the $2^{\text {nd }}$ phase due to high metabolism that must be released to the environment in order to achieve a neutral condition (production of heat $=$ release of heat). With the beginning of the $4^{\text {th }}$ phase $(6 \mathrm{~km} / \mathrm{hr})$, the metabolism rate increases, and therefore, a continuous increase in core temperature throughout this phase is noticed. In contrast, the skin temperature that was increasing at the beginning, started to decrease after some time. This fall in temperature is continued until the end of the first half of the $5^{\text {th }}$ phase $(0 \mathrm{~km} / \mathrm{h})$. This is due to sweating and the resulting heat release by evaporation from the skin. 


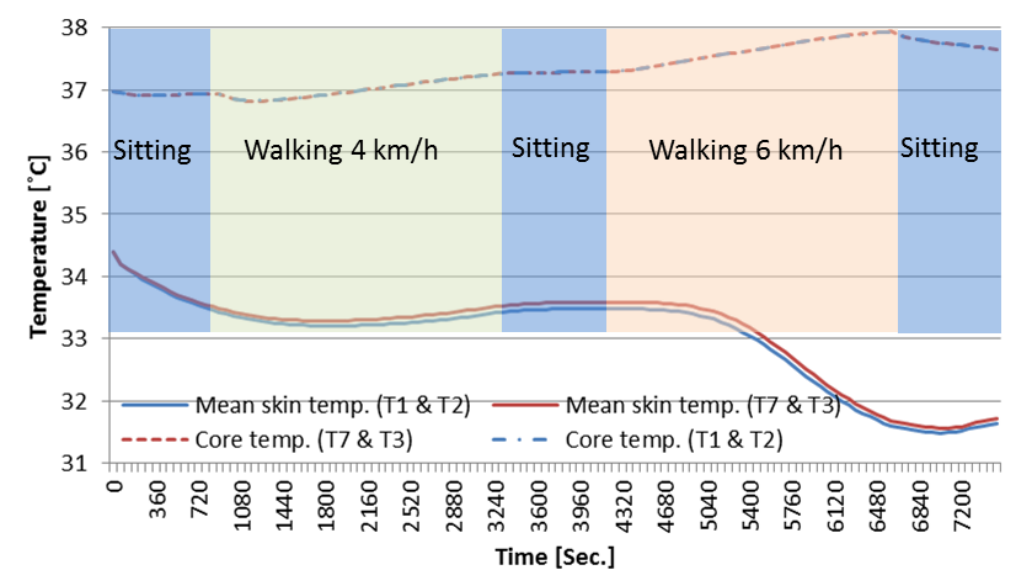

Fig. 4. Comparison of core body and skin temperature during thermal simulation in both cases.

The visual results of changes in temperature of clothing surface, skin and microclimate at time step $3600 \mathrm{sec}$. across the body are presented in Fig. 5

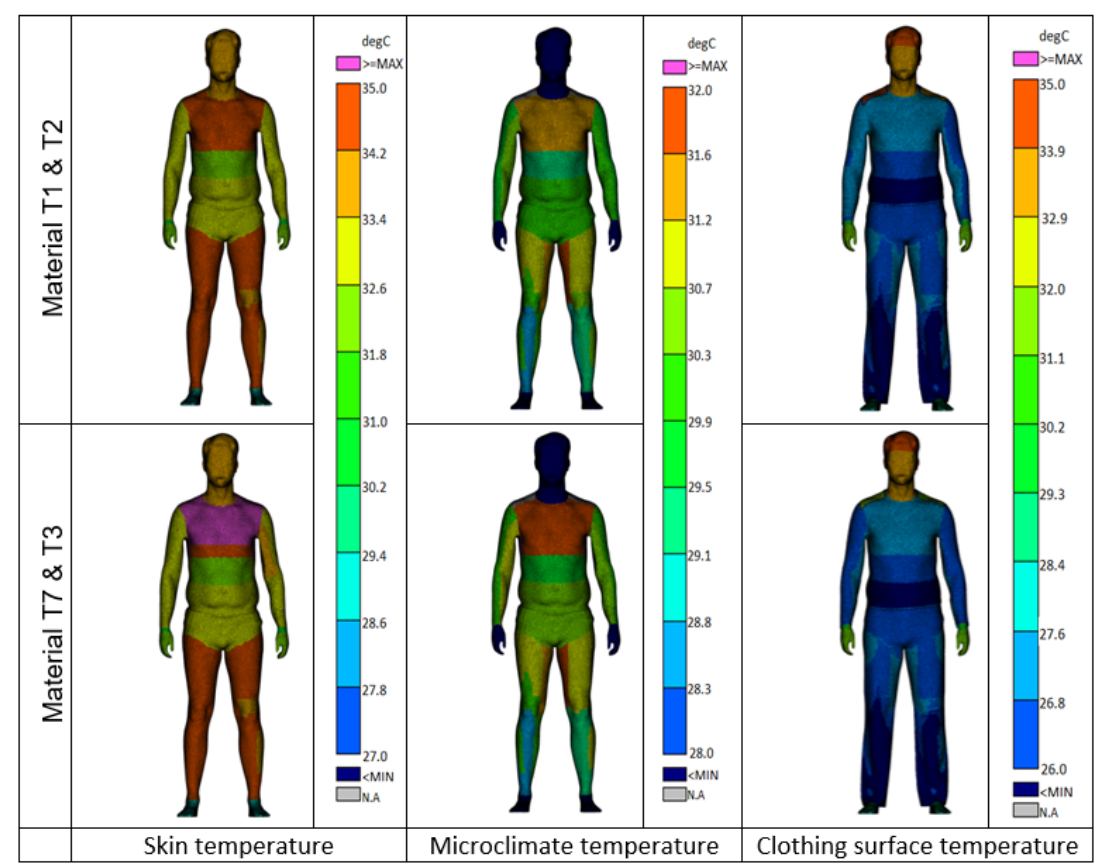

Fig. 5. Skin, microclimate, and clothing surface temperatures at time step $3600 \mathrm{sec}$. during the thermal simulation

Thermal comfort assessments of the investigated pieces of clothing in terms of dynamic thermal sensation (DTS) is illustrated in Fig. 6. The dynamic thermal sensation index (DTS) on a 7-point ASHRAE-scale (-3 - cold, -2 - cool, -1 - slightly cool, 0 - neutral, +1 - slightly warm, +2 - warm, $+3-$ hot). DTS has been validated for the sudden changing of environmental parameters as well as steadystate conditions like 1 or 3 hours exposure. Fiala developed a function for the DTS index with the variables; core body temperature, mean skin temperature and its gradient. The results show that in both cases the DTS index drops suddenly to the value of -2 once simulation begins due to the outside environment condition. Subsequently, it increased continuously till the end of the $2^{\text {nd }}$ phase until it reaches a value of 0.3 , which remains nearly constant throughout the sitting phase ( $3^{\text {rd }}$ phase), i.e. an almost neutral thermal sensation. When the $4^{\text {th }}$ phase $(6 \mathrm{~km} / \mathrm{h})$ begins, a sharp increase in the DTS index from 0.3 to 1 in addition to minor variations occur until the end of the simulation. This is due to the increase in core and skin temperature at the beginning of the $4^{\text {th }}$ phase as shown in Fig. 4. The skin temperature starts to decrease after some time intervals $(400 \mathrm{sec})$, therefore the DTS index value stops rising and remains at approx. 1. 


\section{Dynamic thermal sensation (DTS)}

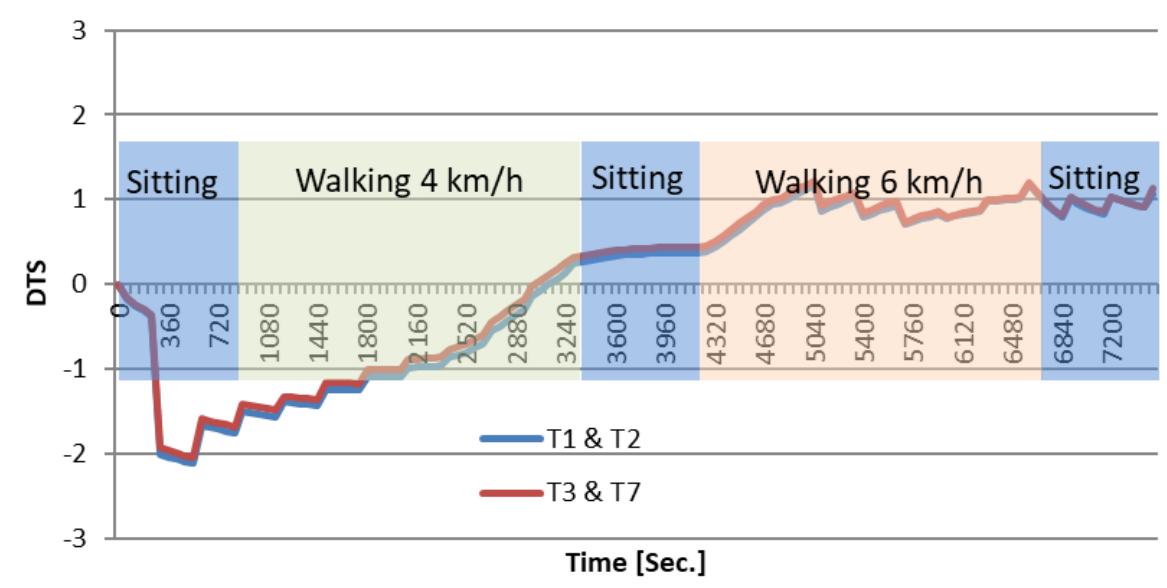

Fig. 6. Assessment of the dynamic thermal sensation for both pieces of clothing

\section{Conclusion}

The method introduced in this paper includes clothing drapability, the human body shape, and the thermoregulation of the human body according to different activity levels. It offers a holistic solution to predict the thermal comfort of clothing. Moreover, the presented method is very useful for designing sports and works garments, where thermal comfort plays an important role for the wearer's performance.

\section{Reference}

[1] "ANSI/ASHRAE Standard 55-2013, Thermal Environmental Conditions for Human Occupancy," pp. 1-11, 2010.

[2] K. Parsons, Human thermal environments, Second. London and New York: Taylor and Francis Group, 2003.

[3] A. Psikuta, "Development of an 'artificial human' for clothing research," De Montfort University Leicester, 2009.

[4] "Vitronic." [Online]. Available: https://www.vitronic.com/industrial-and-logisticsautomation/sectors/3d-body-scanner.html.

[5] "GRAFIS." [Online]. Available: http://www.grafis.de/. [Accessed: 10-Jun-2017].

[6] "Lectra." [Online]. Available: http://www.lectra.com/en. [Accessed: 10-Jun-2017].

[7] "Theseus FE." [Online]. Available: http://www.theseus-fe.com/simulation-software/humanthermal-model. [Accessed: 03-Oct-2017].

[8] D. Fiala, K. J. Lomas, and M. Stohrer, "A computer model of human thermoregulation for a wide range of environmental conditions: the passive system," J. Appl. Physiol., vol. 87, no. 5, pp. 1957-1972, Nov. 1999.

[9] M. Awais and S. Krzywinski, "Method Development for Modeling, Designing, and Digital Representation of Outdoor and Protective Clothing," in Functional Textiles and Clothing, A. Majumdar, D. Gupta, and S. Gupta, Eds. Singapore: Springer Singapore, 2019, pp. 205-218. 